\title{
28 GHz Microstrip Patch Antennas for Future 5G
}

\author{
Safpbri Johari, Muhammad Abdul Jalil, Shaifol Ifrad Ibrahim, Mohd Nazry Mohammad and Norhafiza \\ Hassan \\ Department of Electrical Engineering, Ungku Omar Polytechnic, \\ Jalan Raja Musa Mahadi, 31400, Ipoh, Perak, Malaysia
}

\begin{abstract}
Recently, the industry and academia there is significant activity in research and development towards the next generation micro and Pico cellular wireless Networks (5th generation). This paper presents, a structure design of microstrip patch antenna array operate at the central frequency of $28 \mathrm{GHz}$ waveband is proposed. The patch antenna array consists of four elements with rectangular patch and uniform distribution. It has a compact size of $26.51 \times 20.37 \mathrm{~mm}$ with operating frequency at $28 \mathrm{GHz}$. The inset feed technique is used for the matching between radiating patch and the $50 \Omega$ microstrip feedline. The proposed $2 \times 2$ antenna array successfully improve the antenna gain up to $8.393 \mathrm{~dB}$ compare to existing CRLH TL CPW antenna with $2.99 \mathrm{~dB}$, wideband antenna with $7.1 \mathrm{~dB}$ and $3.7 \mathrm{~dB}$ for broadband elliptical-shaped slot antenna. As a conclusion, the directivity of $10.13 \mathrm{db}$ and efficiency is higher than $80 \%$ considered as a potential candidate for the $5 \mathrm{G}$ wireless networks and applications.
\end{abstract}

Key words: microstrip antenna, array antenna, $5 \mathrm{G}$, directivity, radiation pattern, $\mathrm{S}$ parameters, $28 \mathrm{GHz}$

\section{INTRODUCTION}

An antenna is an electrical device that can converts radio frequency fields into alternating current and vice versa. Recently, future fifth generation wireless communication networks $(5 \mathrm{G})$ requires antenna can support wide bandwidth because of higher data rate [1][2][3][4]. The traffic can be identified from the used bandwidth analysis in global mobile data by Cisco [5]. To achieve this goal, the important of milimeter wave frequencies seems to be inescapable because of the large of spectrum that could be mace accessible for that reason [2]. From these milimeter wave bands, the 28 $\mathrm{GHz}$ particular interest defined from $\mathrm{Ka}$ band as frequencies range $26.5-40 \mathrm{GHz}$ [2] and now low cost antenna are being research and developed [6][7][8][9][10][11][12]. The $28 \mathrm{GHz}$ band is currently available spectrum over $1 \mathrm{GHz}$ of bandwidth [13], and also directions has just begun moving to empower outdoor operation [2]. Base on this reason, low profile antenna are required when the cost, size, weight ease of installation, performance and aerodynamic profile are important. The required not only for the government application but for many other commercial applications [1]. The antenna with low profile design, conformability to planar surface and also non-planar surface, low manufacturing cost, easy to fabricate, mechanically robust when mounted on rigid surface and lastly compatible with MMIC. The advantage from physical view, they are very versatile in operating frequency, pattern and impedance when particular patch and mode are selected. Next issue for milimeter wave radio connections is the inferred little gap of the now substantially smaller antenna. The little gap issue shows itself in the Friss condition as loss proportional to carrier frequency and is frequently incorrectly credited to propagation [2]. The problem of small aperture antenna easily overcomes by antenna array with gains [14][15][16]. This improve gain is require in obstructed radio environment where, among others, human bodies are likely blockers of the milimeter wave interface [17]. Effect on this, low profile antenna are required when the cost, size, weight, ease of installation, performance and aerodynamic profile are important. Microstrip antenna can be a perfect candidate to meet all requirements above [18]. Besides,

Corresponding Author: Safpbri Johari, Department of Electrical Engineering, Ungku Omar Polytechnic, Jalan Raja Musa Mahadi, 31400, Ipoh, Perak, Malaysia, 0189577443 
there is requirement for planning antenna array to accomplish higher gain to conquer the way misfortune because of the air ingestion of electromagnetic waves at higher frequencies. However, a few design issues can affect an antenna performance [19]. First of all, commercial substrates used to fabricate antenna do not indicate values of relative dielectric permittivity $(\mathrm{Er})$ beyond $10 \mathrm{GHz}$. The issue turns crucial when designing the antenna at much higher frequencies, since the $\mathrm{Er}$ value partly determines geometrical parameters of the patch. In the remainder of this work, investigation of inside feed square microstrip patch antenna which can operate in Ka band phased array will be carrying out. Simulation results from a commercial 3D electromagnetic simulator are provided. It will be investigated the performance of the single and array antenna in term of bandwidth, gain and radiation pattern.

\section{SPECIFICATION AND MATERIAL SELECTION}

Picking a substrate is as vital as the design [20]. The substrate itself is a piece of the antenna and contributes significantly to its radiation properties. Many different factors are considered in picking substrate, for example thickness, dielectric constant, stiffness as well as loss tangent. The dielectric constant should be as low as conceivable to energize fringing and hence radiation. A thicker substrate should also be picking since it increases the impedance bandwidth.

Moreover, using a thick substrate would in accuracy since most microstrip antenna models use a thin substrate approximation in the analysis. Substrates which are lossy at higher frequencies not be used for obvious reasons [21]. The choice of a stiff or soft board basically depends on the application at hand. In this project, Ultralam@3850HT from Rogers is chosen as the dielectric material base on good performance on more $10 \mathrm{GHz}$ [22].

\section{PROPOSED ANTENNA DESIGN AND DEVELOPMENT}

\section{A. Single Microstrip Patch Antenna}

Working at $28 \mathrm{GHz}$, microstrip patch antenna one of ideal solution for cost sensitive radio applications because of small size, low profile, simplicity of coordination and ease of integration in portable wireless devices [23][24]. In this case, it has tendency to be less effective and restricted in data transmission and range to cover.
Fig. 1 show the geometry of the proposed single patch microstrip antenna used as a building block for the $2 \times 2$ array antenna. The antenna with a ground width of $7.6 \mathrm{~mm}$ and a ground length of $5.4 \mathrm{~mm}$ is fully copper grounded set the resonance frequency at $28 \mathrm{GHz}$. This future proposed antenna has geometric size is $3.8 \mathrm{~mm} \mathrm{x}$ $2.9 \mathrm{~mm}$ in width and length.

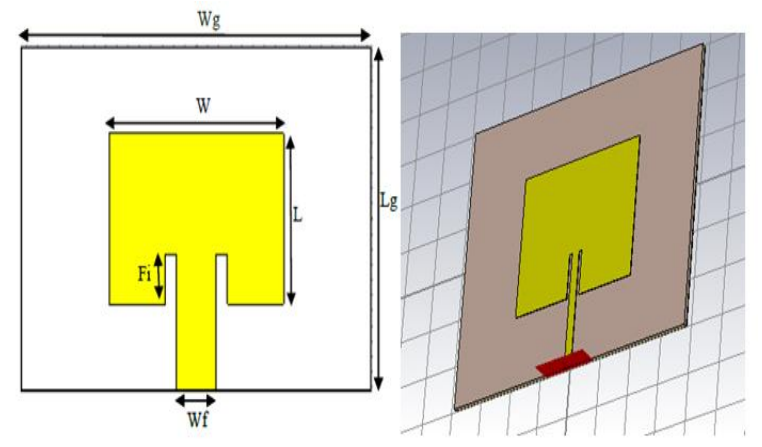

Fig. 1: Geometry and dimensions of the proposed 5G single microstrip patch antenna, (a) Geometry. (b) Illustrated in CST.

Table 1: Proposed Single Antenna Dimensions

\begin{tabular}{|c|c|}
\hline Parameter & Value(mm) \\
\hline Ground Plane Length & 5.4 \\
\hline Ground Plane Width & 7.6 \\
\hline Patch Length & 3.05 \\
\hline Patch Width & 4.4 \\
\hline Line Length & 1.0 \\
\hline Line Width & 0.2 \\
\hline Substrate & 2.9 \\
\hline
\end{tabular}

The rectangular patch is chosen because it is convenient to design and analyze. The rectangular patch also has large impedance bandwidth due to it broader shape compare to other types. To legitimately match single patch antenna and the feed transmission line which is $50 \Omega, 0.9 \mathrm{~mm}$ is picked for an inset to move the feed position far from the edge. While for the gap between feed line and patch is $0.2 \mathrm{~mm}$ to patch keeps small effect in coupling. Table 1 demonstrates the physical parameter and optimization that might be considered in designing single element patch antenna.

\section{B. Microstrip Antenna Arrays}

On future (5th generation) applications, the antenna need a higher gain and directive beam that can be controlled in specific direction. It may be difficult to accomplish such high gain by used a single antenna [25]. However, several small antennas can be gathered together in array antenna to obtain such high increase 
gain directive pattern that can be electronically checked in a specific direction. Forming the array antenna radiation pattern can be accomplished by fitting the magnitude and phase of the current feeding individual elements of the array antenna.

Linear arrays have narrow radiation beam in the plane containing the array axis while have a wide beam in the orthogonal plane. This pattern of linear array is helpful in the case of (5th generation) mobile applications as it requires 1-D checking to cover large area.

Total dimension of array antenna with four elements is $26.51 \mathrm{~mm} \times 20.37 \mathrm{~mm}$ in width and length. Fig. 2 is the geometrical configuration of the proposed four elements antenna array is presented. The uniform distribution is used in this array with the same value of amplitude for each is done by providing equal input impedance for each patch. The transmission line that connects to each patch has an input impedance of $50 \Omega$.

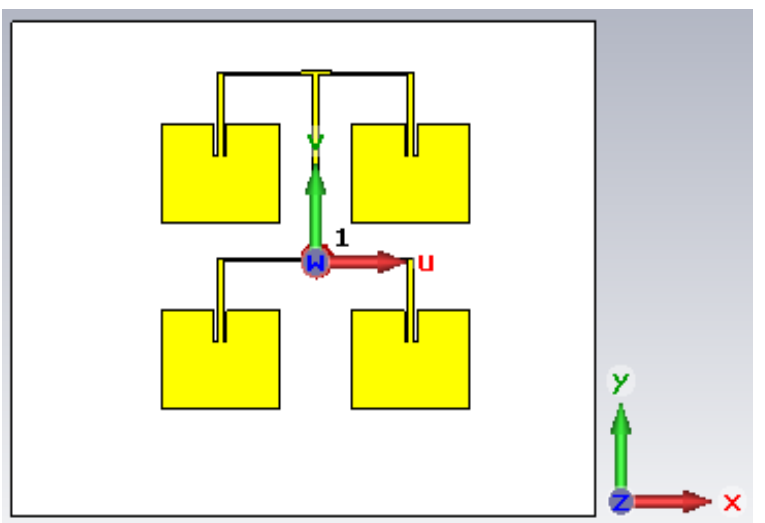

Fig. 2: Geometrical configuration of the proposed four element $5 \mathrm{G}$ antenna array.

\section{Feed Network}

To accomplish more directivity and gain, arrays of patch elements can be utilized as part of combination with a feed network. Methods of distributing electrical energy to each patch include microstrip line, aperture coupling and proximity coupling [25].

The array antenna is fed from the bottom using $50 \Omega$ coaxial line and the input feed lines for the patches are chosen to be at the radiating edge. Thus, no mismatch exists at the input of the patches. The quarter wavelength transformer is used to fix the $100 \Omega$ line to the $25 \Omega$ equivalent resistance of the parallel two $50 \Omega$ lines.

\section{RESULT AND DISCUSSION}

Designing and simulation of the proposed single patch antenna and array antenna is performed using Computer Simulation Technology (CST) Microwave Studio [3].

\section{A. Simulation Single Antenna}

The characterization result of a single element antenna in term of reflection coefficient and radiation pattern is shown in Fig. 3 and Fig. 4. The calculated reflection coefficient shows the designed antenna operating at a frequency of $28 \mathrm{GHz}$ with a value of $|\mathrm{S} 11|$ is better than $15 \mathrm{~dB}$ at $28 \mathrm{GHz}$. The $-10 \mathrm{~dB}$ working bandwidth of the designed antenna is about $400 \mathrm{MHz}$ ranges from the frequency $27.8 \mathrm{GHz}$ to $28.2 \mathrm{GHz}$ as shown in Fig 3. The designed antenna has a directional radiation pattern with the antenna gain of $6.22 \mathrm{~dB}$ as shown in Fig. 4. A half power $(3 \mathrm{~dB})$ beamwidth of $84.5^{\circ}$ and side lobe level of $-15.7 \mathrm{~dB}$ are achieved by the single element antenna. VSWR for a single element antenna is shown in Fig 5. From this result, the value of VSWR is 1.022294 at frequency $28 \mathrm{GHz}$ which is very efficient in manufacturing process. It should be less than 2. The minimum VSWR can get the better performance for the antenna.

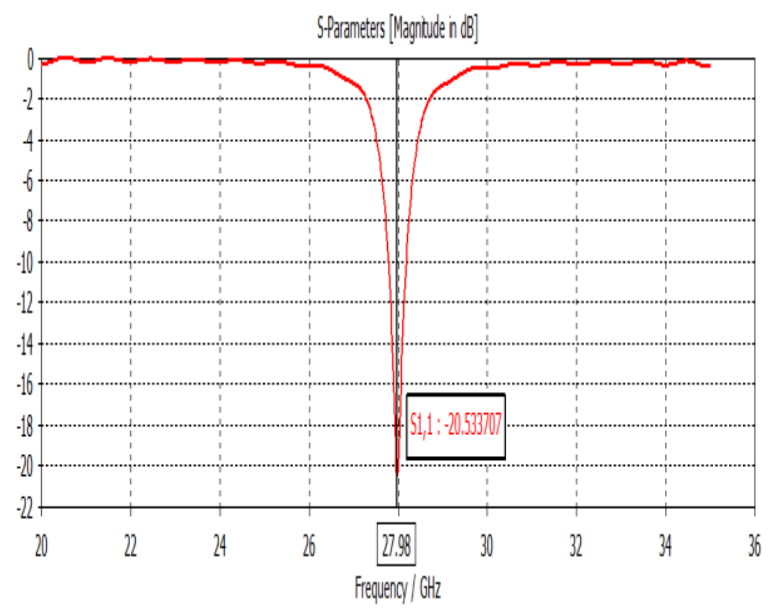

Fig. 3: Reflection coefficient $|\mathrm{S} 11|$ versus frequency of proposed single element 1 x 1 antenna at $28 \mathrm{GHz}$. 


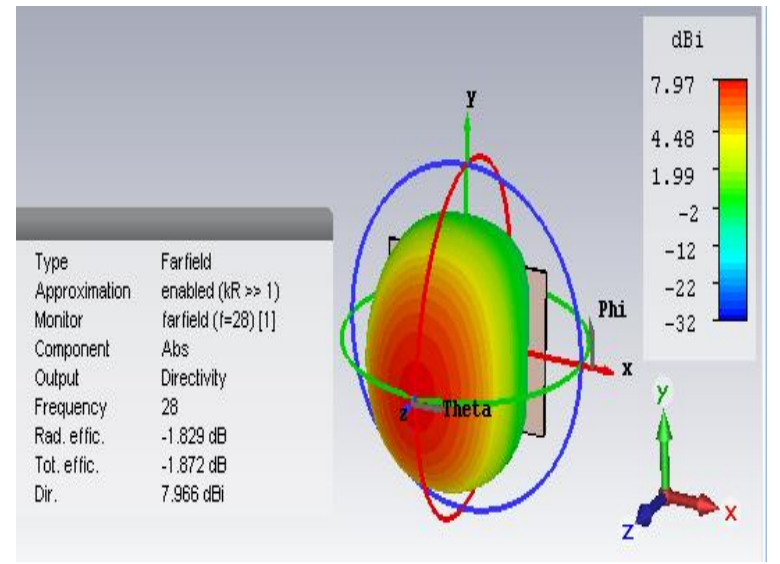

Fig. 4: Radiation patterns of proposed single element antenna at $28 \mathrm{GHz}$.

\section{B. Simulation Array Antenna}

A broader match is achieved for the $2 \times 2$ array as shown in Fig. 5. More than $15 \mathrm{~dB}$ of return loss is available over a bandwidth of $400 \mathrm{MHz}$ and the antenna usable frequency range is also extended.

The simulated results of the reflection coefficients $|\mathrm{S} 11|$ for the proposed for element 5G antenna array is illustrated in Fig. 6. The uniform distribution is used in this array with the same value of amplitude for each patch is done by providing equal input impedance for each patch. It is apparent that the proposed antenna array has a good impedance matching at the desired frequency band of $28 \mathrm{GHz}$ for $|\mathrm{S} 11|$ less than $-10 \mathrm{~dB}$.

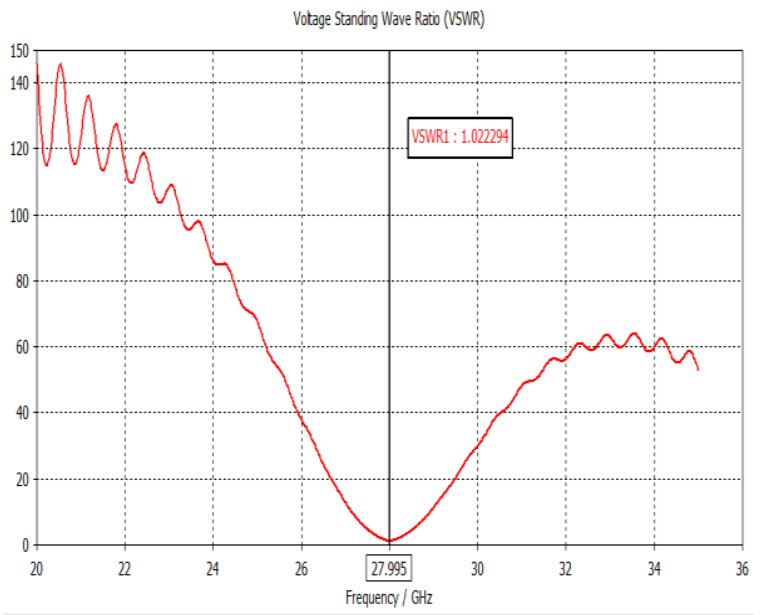

Fig. 5: VSWR of proposed single element antenna at $28 \mathrm{GHz}$.

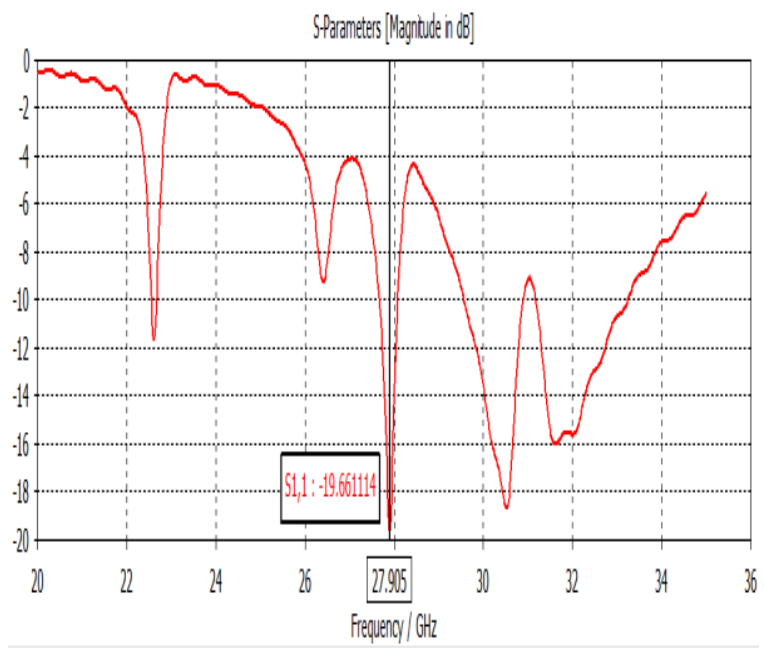

Fig. 6: Reflection coefficient $|\mathrm{S} 11|$ versus frequency of proposed four element $2 \times 2$ antenna array at $28 \mathrm{GHz}$.

Fig. 7 is result for the simulated radiation pattern of the proposed antenna array. A stable gain with a value of $8.393 \mathrm{dBi}(+2.174 \mathrm{dBi}$ compared to a single antenna element) at $28 \mathrm{GHz}$ us observed. This obtain gain is improved which is $126.83 \%$ higher compared to [10], $180.70 \%$ higher than [11] and $18.21 \%$ better to [12]. Simulated results demonstrate that the antenna array is characterized by bidirectional patterns. VSWR for proposed antenna array is shown in Fig 8. From this result, the value of VSWR is 1.2320898 at frequency 28 $\mathrm{GHz}$ which is also efficient in manufacturing process. From the result, it less than 2 and consider as a good result.

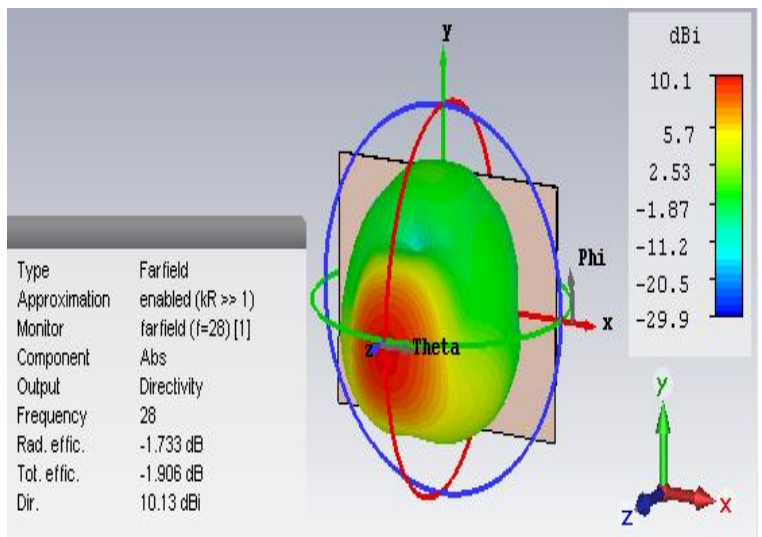

Fig. 7: Radiation patterns of proposed four element antenna array at $28 \mathrm{GHz}$. 


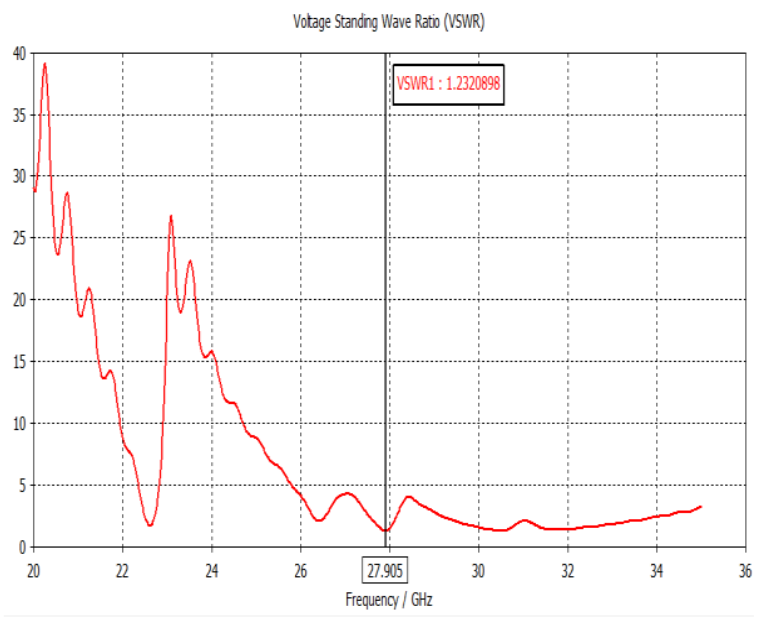

Fig. 8: VSWR of proposed four element 2 x 2 antenna array at $28 \mathrm{GHz}$.

\section{Comparison Single and Array Antenna}

Larger array size will transform to higher gain and directivity of the array antenna but also increasing the feed networks. But, ever increasing feed networks introduce additional losses between the feed point and radiating patch elements.

Table 2: Proposed Antenna Simulation Results

\begin{tabular}{|c|c|c|}
\hline $\begin{array}{c}\text { Simulation } \\
\text { Results }\end{array}$ & $\begin{array}{c}\text { Single Element } \\
\mathbf{1} \text { x 1 }\end{array}$ & $\begin{array}{c}\text { Four Elements } \\
\mathbf{2 ~ x ~ 2}\end{array}$ \\
\hline Gain (dBi) & 6.219 & 8.393 \\
\hline Directivity (dBi) & 8.002 & 10.130 \\
\hline Beamwidth (Deg) & 84.5 & 79.0 \\
\hline Efficiency (\%) & 77.72 & 82.85 \\
\hline Bandwidth (MHz) & 400 & 400 \\
\hline
\end{tabular}

Simulated result between single element antenna and four element antenna is shown in Table 2. This results are calculated for nominal values of Rogers Ultralam@3850HT substrate with dielectric constant $\varepsilon r=2.9$ and loss tangent $\tan \delta=0.0025$. Fig. 9 is show the simulated realized gain for single and array antenna with respect of frequency. The result show that the array antenna is above than the single antenna and it is suited for $28 \mathrm{GHz}$.

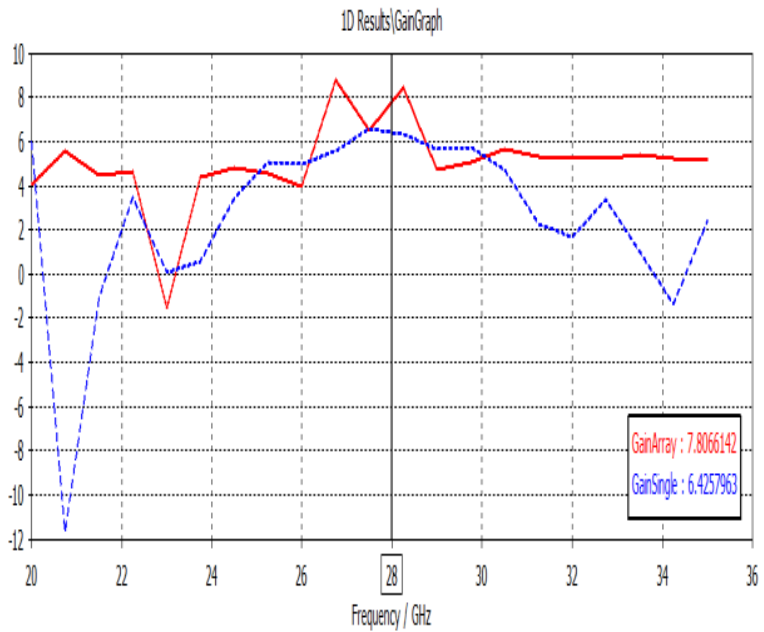

Fig. 9: Numerical results of realized gain vs. frequency.

\section{CONCLUSION}

In this work, the simple printed patch antenna array was proposed. The antenna was designed for $28 \mathrm{GHz}$ operation with four elements in array structure using microstrip methods. Impedance and phase matching techniques were designed using a quarter wavelength transformer and transmission line. The antennas with single and four elements in array were analyzed using electromagnetic analysis software. The results at 28 $\mathrm{GHz}$ show that $8.393 \mathrm{~dB}$ can be achieved for antenna gain compared to the previous work: $3.7 \mathrm{~dB}$ in [9], 2.99 $\mathrm{dB}$ in [13] and $7.1 \mathrm{~dB}$ in [14]. Caused by enhanced performance, this proposed antenna quality serve as a good option for $5 \mathrm{G}$ which requires low topology and high gain.

\section{ACKNOWLEDGMENTS}

The authors acknowledge the financial support from Ungku Omar Polytechnic (PUO), Perak, Malaysia

\section{REFERENCES}

[1] W. Roh et al., "Millimeter-wave beamforming as an enabling technology for 5G cellular communications: Theoretical feasibility and prototype results," IEEE Commun. Mag., vol. 52, no. 2, pp. 106-113, 2014.

[2] B. S. Rangan, T. S. Rappaport, and E. Erkip, "Millimeter-Wave Cellular Wireless Networks: Potentials and Challenges," vol. 102, no. 3, 2014.

[3] C. S. T. S. Suite, "CST STUDIO SUITE 2012 : S ystem A ssembly and M odeling," 2012.

[4] W. I. F. I. O. N. S. T. Ac, L. O. V Erma, M. O. F. Akharzadeh, P. E. T. Echnologies, and I. Nc, "ACCEPTED FROM OPEN CALL THE NEED 
FOR MULTI-GIGABIT WIFI MULTI-GIGABIT WIFI STANDARDS," no. December, pp. 30-35, 2013.

[5] Cisco, "Cisco Visual Networking Index: Global Mobile Data Traffic Forecast Update, 20122017\&nbsp; [Visual Networking Index (VNI)]," pp. 2015-2020, 2012.

[6] H. Aliakbari, A. Abdipour, R. Mirzavand, A. Costanzo, and P. Mousavi, "A single feed dual-band circularly polarized millimeter-wave antenna for $5 \mathrm{G}$ communication," 2016 10th Eur. Conf. Antennas Propagation, EuCAP 2016, 2016.

[7] O. M. Haraz, M. M. M. Ali, S. Alshebeili, and A. R. Sebak, "Design of a $28 / 38 \mathrm{GHz}$ dual-band printed slot antenna for the future $5 \mathrm{G}$ mobile communication Networks," IEEE Antennas Propag. Soc. AP-S Int. Symp., vol. 2015-October, pp. 1532-1533, 2015.

[8] M. M. M. Ali and A. R. Sebak, "Dual band (28/38 $\mathrm{GHz}$ ) CPW slot directive antenna for future $5 \mathrm{G}$ cellular applications," 2016 IEEE Antennas Propag. Soc. Int. Symp. APSURSI 2016 - Proc., pp. 399400, 2016.

[9] O. M. Haraz, N. Ashraf, S. Almorqi, H. Shaman, S. A. Alshebeili, and A. R. Sebak, "Millimeter-wave microstrip diplexer using elliptical open-loop ring resonators for next generation $5 \mathrm{G}$ wireless applications," Microw. Opt. Technol. Lett., vol. 58, no. 1, pp. 106-110, 2016.

[10] M. M. M. Ali, O. Haraz, S. Alshebeili, and A. R. Sebak, "Broadband printed slot antenna for the fifth generation (5G) mobile and wireless communications," 2016 17th Int. Symp. Antenna Technol. Appl. Electromagn. ANTEM 2016, pp. 5-6, 2016.

[11] A.-C. Bunea, F. Craciunoiu, and G. Sajin, " $28 \mathrm{GHz}$ CRLH antenna on silicon substrate," Eur. Microw. Week 2011 "Wave to Futur. EuMW 2011, Conf. Proc. - 41st Eur. Microw. Conf. EuMC 2011, no. October, pp. 579-582, 2011.

[12] S. Ershadi, A. Keshtkar, A. H. Abdelrahman, X. $\mathrm{Yu}$, and $\mathrm{H}$. Xin, "Design of wideband unit-cell element for 5G antenna arrays," in 2015 Asia-Pacific Microwave Conference (APMC), 2015, pp. 1-3.

[13] T. S. Rappaport et al., "Millimeter wave mobile communications for $5 \mathrm{G}$ cellular: It will work!," IEEE Access, vol. 1, pp. 335-349, 2013.

[14] G. Zhang, S. Pu, X. Xu, Y. Liu, and C. Wang, "Design of $60-\mathrm{GHz}$ microstrip antenna array composed through circular contour feeding line," 2016 Asia-Pacific Int. Symp. Electromagn. Compat. APEMC 2016, pp. 1010-1013, 2016.
[15] R. R. Selvaraju, M. R. Kamarudin, M. H. Jamaluddin, M. H. Dahri, and C. Y. Low, "Compact 4-Element beam steerable printed adaptive array antenna for 5G application," 2016 IEEE Asia-Pacific Conf. Appl. Electromagn. APACE 2016, no. December, pp. 30-33, 2016.

[16] O. M. Haraz, M. M. Ashraf, and S. Alshebili, " $8 \times 8$ Patch antenna array with polarization and space diversity for future 5G cellular applications," 2015 Int. Conf. Inf. Commun. Technol. Res. ICTRC 2015, no. c, pp. 258-261, 2015.

[17] M. Gapeyenko et al., "Analysis of Human-Body Blockage in Urban Millimeter-Wave Cellular Communications," 2016.

[18] S. K. Prajapati and D. C. Dhubkarya, " $2 \times 2$ Microstrip Antenna Array Design for Bandwidth Enhancement Using four arm Spiral Electromagnetic Band Gap ( EBG ) Structure," vol. 4, no. 12, pp. 2821-2824, 2015.

[19] M. A. Matin, "Review on Millimeter Wave Antennas- Potential Candidate for 5G Enabled Applications," Adv. Electromagn., vol. 5, no. 3, p. 98, 2016.

[20] T. S. Rappaport, J. N. Murdock, and F. Gutierrez, "State of the Art in 60-GHz Integrated Circuits and Systems for Wireless Communications," Proc. IEEE, vol. 99, no. 8, pp. 1390-1436, 2011.

[21] D. Sheet, “Ultralam ${ }^{\circledR} 3000, ”$ pp. 1-4.

[22] W. Ahmad and W. T. Khan, "Small form factor dual band $(28 / 38 \mathrm{GHz})$ PIFA antenna for $5 \mathrm{G}$ applications," 2017 IEEE MTT-S Int. Conf. Microwaves Intell. Mobility, ICMIM 2017, no. Icmim, pp. 21-24, 2017.

[23] J. S. Park, J. B. Ko, H. K. Kwon, B. S. Kang, B. Park, and D. Kim, "A Tilted Combined Beam Antenna for 5G Communications Using a $28-\mathrm{GHz}$ Band," IEEE Antennas Wirel. Propag. Lett., vol. 15, pp. 1685-1688, 2016.

[24] N. A. Zainal, M. R. Kamarudin, Y. Yamada, N. Seman, M. Khalily, and M. Jusoh, "Sidelobe reduction of unequally spaced arrays for 5G applications," 2016 10th Eur. Conf. Antennas Propagation, EuCAP 2016, vol. 5880, pp. 4-7, 2016.

[25] C. a. Balanis, Antenna Theory: Analysis and Design, vol. 28, no. 3. 2012. 